\title{
Redes sociales, capital social y acción colectiva en dos territorios campesinos de la región de La Araucanía, en Chile, para enfrentar problemas asociados al acceso al agua*
}

\author{
Francisca Fonseca \\ Universidad de La Frontera. Departamento de Ciencias Sociales y Centro de Investigaciones \\ Sociales Sur CIS-SUR \\ francisca.fonseca@ufrontera.cl
}

René Montalba

Universidad de La Frontera. Instituto del Medio Ambiente y Sustentabilidad y Facultad de Ciencias Agropecuarias y Forestales

rene.montalba@ufrontera.cl

\section{Mauricio García}

Universidad de La Frontera. Departamento de Ciencias Sociales y Centro de Investigaciones Sociales Sur CIS-SUR mauricio.garcia@ufrontera.cl

\section{Resumen}

El artículo presenta un análisis de las redes sociales y el capital social como condiciones necesarias para el surgimiento de la acción colectiva, específicamente, en comunidades campesinas de la región de La Araucanía, para enfrentar problemas de acceso al agua. Chile, a diferencia de la mayoría de los países de América Latina, posee un sistema de asignación, distribución y gestión hídricas basado en principios de mercado, es decir, el agua deja de ser un bien común y se transforma en un bien privado desvinculado de la propiedad de la tierra, con lo cual se despoja a los campesinos e indígenas de las aguas que tradicionalmente han utilizado. El aumento de los conflictos por el agua en Chile no se debe exclusivamente a problemas asociados a la escasez, sino a las particularidades del modelo de gestión institucionalizado y a la restricción para generar acción colectiva local que permita la gestión sustentable del recurso. Metodológicamente, se aplicaron encuestas y se realizaron análisis de redes sociales. Los principales resultados muestran que las redes sociales tienen propiedades estructurales que no favorecerían la formación del capital social necesario para

* Este artículo es parte de los resultados del proyecto FONDECYT Regular 2014, №1141249, financiado por la Comisión Nacional de Ciencia y Tecnología de Chile. 
la acción colectiva. No obstante, al analizar las propiedades relacionales de las redes, se observa que los escasos vínculos existentes son lazos fuertes, a partir de los cuales se podría realizar gestión de redes, con el propósito de establecer articulaciones sinergéticas orientadas a transformar la estructura de las redes, haciéndolas más cohesivas, y, de este modo, crear condiciones para la formación de acción colectiva en las áreas de estudio.

Palabras clave: campesino; cooperación social; organizaciones; acceso al agua; gestión del agua; información; reciprocidad; normas sociales; estructura de red; gobernanza.

Abstract. Social networks, social capital, and collective action in two rural areas of La Araucania region, Southern Chile, to address problems related to the access to water

The article presents an analysis of social networks and social capital as necessary conditions for the emergence of collective action, specifically in rural communities in La Araucanía Region to address problems related to the access to water. Chile, unlike most Latin American countries, has a water distribution and management system based on market principles, in which water is no longer a common good but a private one disconnected from land property, thus depriving small farmers and indigenous peoples from access to the water they have traditionally used. Increasing water conflicts in Chile are not only due to problems associated with scarcity, but because of the model of institutionalized management and restrictions on local collective action that allows the sustainable management of water. Methodologically, surveys were administered and social network analysis was performed. The main results show that social networks have structural characteristics that do not allow the formation of the social capital needed for collective action. However, there are few links with deep characteristics from which it is possible to establish network management and synergistic connections that can transform the structure of the networks, making them more cohesive, thus creating the necessary conditions for the formation of collective action in the study areas.

Keywords: farmer; social cooperation; organizations; access to water; water management; information; reciprocity; social norms; network structure; governance.

\author{
Sumario \\ 1. Introducción 4. Resultados \\ 2. Antecedentes teóricos. Acción 5. Conclusiones \\ colectiva, capital social y redes sociales \\ Referencias bibliográficas
}

3. Metodología

\title{
1. Introducción
}

Los conflictos en torno al agua son cada vez más frecuentes. A nivel mundial, el agua se ha convertido en un recurso escaso y altamente demandado. Según el Informe de las Naciones Unidas sobre el Recurso Hídrico en el Mundo, se prevé que, para el año 2050, la demanda de agua, solo del sector agrícola, aumentará un 19\%. La ONU plantea que es muy poco probable que pueda satisfacerse la demanda de agua en continuo aumento, con soluciones relacio- 
nadas con el suministro o solo considerando aspectos técnicos. Por esta razón, las soluciones deben tomar en cuenta la capacidad de gestionar las necesidades y encontrar la forma de equilibrar y obtener un máximo beneficio del agua (UNESCO, 2012). Dado lo anterior, es prioritario considerar enfoques de gestión y de gobernanza de los recursos hídricos como forma de enfrentar la escasez y posibles conflictos sociales.

América Latina es una región con distintas realidades en relación con el acceso al agua, pero, más allá de estas diferencias, puede observarse un aumento en los conflictos sociales vinculados a su acceso, uso, distribución y propiedad, en los que participan distintos actores cuyos intereses tienden a contraponerse: las comunidades campesinas e indígenas, los actores colectivos (organizados en la gestión del agua como recurso de uso común o como usuarios afectados pero no implicados en la solución del conflicto), las organizaciones civiles nacionales, las empresas, los gobiernos locales y el Estado (Mussetta, 2010).

Un aspecto clave a considerar para Chile, a diferencia del resto de los países latinoamericanos, es que el acceso al agua no solo depende de la existencia o no del recurso, sino que se requiere de «derechos de agua». En el año 1981, durante la dictadura militar (1973-1990), se promulgó el Código de Aguas, normativa que establece la propiedad de los recursos hídricos y que incorpora un elemento discriminatorio y restrictivo para su acceso. Es así como este marco político que determina el régimen jurídico del agua, la concibe como "bien nacional de uso público», con lo que se instaura un derecho real de aprovechamiento que, bajo la forma de una concesión privada, otorga el derecho a particulares de adueñarse de las aguas y usarlas como cualquier otro bien privado (Infanti, 2008: 90). Dicha concesión tiene la particularidad de ser gratuita y perpetua, sin que se contemplen normas de caducidad de los derechos, es decir, el agua es un bien privado que es comprado y transado en el mercado correspondiente a dicho recurso. Además, el Código separa los derechos de agua del dominio de la tierra por donde transita y la concesión se otorga a cualquier persona que lo requiera, independientemente de los derechos de los propietarios de los territorios. De esta forma, el Código de Aguas despoja de ella a campesinos, indígenas y, en general, a los usuarios tradicionales de estos recursos.

Los problemas y conflictos por el agua en Chile están presentes en todo el territorio nacional, no son exclusivos de zonas secas o con escasas precipitaciones, por ende, sus causas no pueden solo aducirse a condiciones climáticas o geográficas, sino que, más bien, están directamente relacionadas con el sistema de asignación, distribución y gestión del recurso hídrico, el cual ha generado, en las últimas dos décadas, un notable aumento de conflictos. Según el informe Conflictos por el agua en Chile, publicado en 2010 por la Fundación Chile Sustentable, el Código de Aguas actual implica que, una vez que han sido entregados los derechos de agua a los privados que la solicitan, el Estado ya no vuelve a intervenir, y su reasignación se realiza a través del «mercado de aguas», donde el propietario privado de derechos hídricos los puede arrendar, comprar $y$ vender como cualquier bien inmueble. Si bien, este modelo fue pensado para 
generar mayor competitividad y eficiencia en la asignación de los derechos de agua, lo que ha ocurrido es una concentración de los derechos en grandes empresas privadas, como las hidroeléctricas, las mineras, las agroindustriales y las sanitarias, con un alto detrimento hacia los pequeños campesinos, que, dada la falta de información y acceso a la misma, han sido perjudicados en lo que concierne a la adquisición de derechos de agua, a pesar del uso consuetudinario que estos hayan hecho del recurso (Chile Sustentable, 2012).

En la región de La Araucanía - donde se sitúa la investigación-, considerada como una zona rica en agua, se han ido incrementando de forma notoria los problemas y los conflictos de origen hídrico, principalmente aquellos que confrontan los intereses de las comunidades campesinas e indígenas con los de las empresas forestales, hidroeléctricas, pisciculturas y, recientemente, explotaciones mineras en la zona cordillerana. Cabe destacar que, en la región, según datos obtenidos en la investigación realizada, menos del 30\% de los campesinos (chilenos e indígenas) cuentan con derechos de agua constituidos, mientras que más del $70 \%$ de los derechos están en manos de empresas privadas. La demanda de personas y organizaciones campesinas, principalmente mapuches, por la constitución de derechos de aprovechamiento de aguas subterráneas en su territorio y en La Araucanía, coincide con el agotamiento de los derechos sobre caudales superficiales solicitados por usuarios no indígenas (forestales, acuícolas y agrícolas) y con la monopolización de derechos sobre los principales ríos de la región por parte de empresas hidroeléctricas (Yánez y Molina, 2011). Lo anterior implica que el tema del agua y, en específico, el problema de acceso al recurso debe abordarse como un problema político, donde las capacidades existentes en los territorios para generar estrategias colectivas que les permitan, por ejemplo, acceder a "derechos de agua» y gestionar el recurso, son claves para enfrentar la arbitrariedad del modelo chileno.

En la literatura reciente sobre conflictos en torno al agua, es muy interesante aquella que enfatiza la relevancia de la acción colectiva emprendida por los afectados, quienes se han organizado para visualizar sus demandas interpelativas (Anand, 2007; Campos y Avila-García, 2013; Navarrete, 2008). Esta acción colectiva puede ser contenciosa, entendida desde la teoría de los movimientos sociales como aquella orientada a la protesta y a la presión reivindicativa en representación de intereses compartidos (Tilly y Tarrow, 2007; Tarrow, 2011). En torno a este tipo de acción colectiva, en la teoría de los movimientos sociales, se reconoce crecientemente la importancia de las redes sociales (Della Porta y Diani, 2006; Diani, 2003a), porque favorecen la participación movilizadora y la articulación para formar alianzas empoderadoras. Es decir, se focaliza el análisis teórico y empírico en las redes sociales como una condición necesaria para el surgimiento de la acción colectiva. En este marco, McAdam et al. (2001) proponen que para explicar la acción colectiva contenciosa, es necesario identificar mecanismos causales recurrentes $y$, entre varios, distinguen los mecanismos relacionales que dinamizan las conexiones entre personas, grupos y redes. En este mismo sentido, Tarrow (2011) reconoce la relevancia de las redes en la formación de procesos de movilización, referidos a procesos 
de enmarcación o interpretación de los sucesos, a la creación y apropiación de recursos, organizaciones e instituciones para acceder a oportunidades y evadir amenazas y a la implicación en la acción colectiva, con el fin de sumar adeptos y disuadir a las autoridades.

En torno al análisis de la acción colectiva, además de la teoría de los movimientos sociales, en la actualidad, se desarrolla una integración teórica paulatina entre la teoría de la acción colectiva, con la teoría de redes sociales, y la teoría del capital social, la que se toma como punto de partida (y que se desarrolla en la sección sobre antecedentes teóricos), para establecer como supuesto que, para que exista acción colectiva, es necesaria la presencia de capital social $y$, para que este se forme, deben existir redes sociales con determinadas propiedades estructurales y relacionales.

Entonces, se entiende como condiciones para la emergencia de la acción colectiva, la existencia de redes con una estructura y un tipo de vínculos como los señalados y, de manera complementaria, la existencia de capital social que produzca la acción colectiva. Si la acción colectiva es fundamental para que los afectados por problemas de acceso al agua mejoren su situación, entonces surge la interrogante principal a responder en este artículo, referida a si las condiciones señaladas están presentes, lo que conduce a su estudio en dos territorios rurales de la región de La Araucanía afectados por problemas de acceso al agua. El primero de ellos corresponde al área de estudio de Lumaco, ubicada en el secano costero, con problemas graves de escasez hídrica dadas las escasas precipitaciones y una alta demanda de agua por parte de las plantaciones forestales y la agroindustria. La segunda área de estudio es Curarrehue, ubicada en la cordillera de Los Andes, que presenta altas precipitaciones, pero, a su vez, una alta demanda del recurso por parte de empresas hidroeléctricas, pisciculturas y minería, que se han ido instalando en el territorio en los últimos diez años.

En base a lo señalado, el objetivo fundamental desde el cual se buscó responder a la interrogante planteada fue analizar las condiciones requeridas para el surgimiento de la acción colectiva en las áreas de estudio. En torno a este propósito, un objetivo específico fue caracterizar las propiedades estructurales y relacionales de las redes sociales. En complemento - contando con la evidencia empírica sobre las propiedades de las redes sociales y con un marco teórico que establece la relación entre propiedades de las redes y la formación de capital social-, el segundo objetivo específico fue analizar teóricamente la factibilidad de formación del capital social necesario para generar la acción colectiva en temas de agua en las dos áreas de estudio.

\section{Antecedentes teóricos. Acción colectiva, capital social y redes sociales}

Esta sección tiene como propósito fundamentar nuestro supuesto teórico sobre la cadena explicativa causal, según la cual la acción colectiva requiere, para su surgimiento, la existencia de capital social, y este, a su vez, se formará siempre que las redes sociales tengan una estructura y un tipo de vínculos con determinadas propiedades. 
Para comenzar, en primer lugar, en relación con la acción colectiva, el capital y las redes sociales, es necesario especificar sobre el concepto de acción colectiva, su formación, la importancia del capital social para el surgimiento de la acción colectiva y el papel de las redes sociales en la activación de recursos de capital social. El concepto de acción colectiva, siguiendo a Ostrom (2010a), se refiere a aquella iniciativa social en que se requiere la implicación de más de un individuo que concurra con su esfuerzo para obtener un resultado determinado y, además, las decisiones de los individuos sobre sus acciones son interdependientes, porque cada uno considera las decisiones de los otros.

Los autores de la llamada «teoría de la acción colectiva de primera generación», que analizan los problemas de formación de la acción colectiva, tienen presente el posible conflicto ya advertido por Olson (1992), quien planteaba que el resultado de aquella tiene la forma de un bien público, pues se caracteriza por su oferta conjunta, siendo indivisible, lo que implica que todos los individuos pueden tener acceso en forma simultánea y libre, nadie puede ser excluido de su consumo una vez que está disponible. Así, el problema de la formación de la acción colectiva se refiere a que los individuos decidirán no implicarse en la provisión del bien público, porque pueden maximizar su utilidad si otros asumen los costos de su formación y luego ellos solo internalizan los beneficios derivados de su consumo. Si cada individuo decide como un polizón, ninguno se implicará en la acción colectiva y el bien público no será provisto (Miller, 2007).

Las teorías de segunda generación, en la búsqueda de explicaciones sobre la acción colectiva, ya no consideran supuestos tan restrictivos como los señalados y otorgan relevancia al capital social que posibilita la cooperación necesaria para la acción colectiva (Ahn y Ostrom, 2008; Ostrom, 1994, 2000a; Brondizio et al., 2009). Para analizar el capital social, adoptamos el enfoque estructural, que lo entiende como recursos, tales como la información y las obligaciones de reciprocidad al que acceden los individuos a partir de su inserción en redes sociales (Coleman, 1988a; Herreros, 2004) ${ }^{1}$. La información es relevante, porque se refiere a las acciones pasadas y a las preferencias de los otros a través de lo cual se puede evaluar su confiabilidad, es decir, si son dignos de confianza (Levi, 2001).

Esto no solo tiene relevancia porque un individuo puede tener la expectativa de que los otros también seguirán una regla, lo que influye en su decisión de seguirla (Bicchieri, 2006), sino, además, porque incide en la decisión de implicarse en la acción colectiva si los otros también lo hacen, por lo que la cooperación es condicional. Las estrategias de cooperación son contingentes a

1. Es el enfoque estructural el que establece una relación entre redes y capital social. Este enfoque, que es compartido por autores como Bourdieu (2001), Herreros (2002) y Lin (2005), propone que el capital social está formado por recursos que circulan en las redes sociales o relaciones sociales. Este enfoque difiere del de otros autores, bastante extendido, como el de Putnam (2000), que propone que las redes sociales son capital social. Además, difiere del llamado «enfoque disposicional» del capital social, según el cual el capital social se refiere a valores y actitudes. 
la reciprocidad de los demás, y si los implicados se han labrado una reputación de cooperadores, esa información permite solucionar problemas de coordinación, de modo que cada individuo estará dispuesto a asumir costos para participar en la acción colectiva, porque tendrá la expectativa de que los otros también lo harán y no actuarán como polizones.

A continuación, se establece la relación entre capital social y redes sociales. Si el capital social se refiere a recursos como la información a la que acceden los individuos gracias a su inserción en redes sociales, esa información puede favorecer la confianza, porque permite la formación de creencias sobre cómo fue el comportamiento pasado de otros. Ese mismo tipo de información hace posible que opere el efecto control de las normas sociales para detectar y sancionar a quienes no cooperan. Para ello, es necesario que la red funcione como un dispositivo de observación multilateral, y esto supone, a su vez, que la red debe tener una estructura con determinadas propiedades y, además, que los vínculos que establecen los individuos deben ser de una naturaleza específica (Coleman, 1988a).

Respecto a la estructura de la red o a las propiedades estructurales de ésta, asociada a la acción colectiva, es importante la densidad (Gould, 1993), que expresa la proporción entre el total de vínculos directos reales en relación con el total de vínculos posibles que componen la red (Scott, 2000). En una red con alta densidad, la mayoría de los nodos están directamente conectados entre sí, y estas conexiones son las vías o los circuitos a través de los cuales circulan recursos como la información (Herreros, 2002), que se distribuye rápidamente, con lo cual todos tienen acceso a ella y pueden enterarse de comportamientos oportunistas y sancionarlos, lo que desincentiva este tipo de acciones no cooperativas (Cook et al., 2005). A partir de la teoría del capital social, Coleman (1988b) señala que la información circulará en las redes si existen suficientes canales de distribución representados por las relaciones sociales, lo que permitirá reconocer normas sociales para el control social si las redes tienen suficiente cierre (closure), es decir, si todos o la mayoría de los individuos están directamente conectados entre sí.

El alto nivel de vinculación en las redes puede ser medido, además, a través de los cliques, definidos como un subgrupo de, al menos, tres nodos directamente conectados entre sí (Carrington et al., 2005). En un clique o en una red con alta densidad, los nodos tienen una centralidad de grado similar (entendiendo la centralidad de grados como el número de vínculos directos), esto es, muestran, proporcionalmente, muchos vínculos directos con otros nodos y, por ello, tienen acceso a la información que circula en la red. Los cliques, sobre todo aquellos denominados «solapados», es decir, aquellos en los que un nodo forma parte de más de un clique, constituyen comunidades de comunicación (regiones de la red en las que existe una colección de cliques conectados), donde la información se transmite eficientemente entre sus integrantes gracias a la alta conductividad de la microestructura reticular (Zubcsek et al., 2014). La información es intercambiada con alta intensidad en los subconjuntos de la red y así es posible que, en estos espacios interactivos, opere el efecto control de las 
normas sociales y se desincentive el oportunismo. En el interior de los cliques, dada la alta cohesión relacional, la información favorece el funcionamiento de sistemas de confianza multilateral, que son concebidos, según Coleman (2011), como aquellos en donde las relaciones entre dos nodos se basan en la confianza mutua y en este marco, si en los cliques existen vínculos directos entre todos, esta confianza puede establecerse entre más de dos individuos.

Si bien, el cierre de red, la densidad y los cliques hacen referencia a la estructura de la red, también expresan la naturaleza de los vínculos o de las propiedades relacionales de las redes sociales. En este mismo sentido, Ostrom (2010a) destaca la importancia para la acción colectiva de determinadas cualidades de los vínculos, puntualmente de las interacciones cara a cara que se repiten, porque permitirían tener información sobre el comportamiento pasado de los otros y generar aprendizajes interactivos a través del tiempo, por medio de heurísticas que viabilizan la adopción de las mejores estrategias, considerando la información que se dispone desde el entorno. Además, como señala Axelrod (1996), si los individuos tienen expectativas de que sostendrán relaciones repetidas (iteradas) durante un tiempo suficiente con otros, tienen incentivos para cooperar con ellos privilegiando las ganancias en el largo plazo producto de la reciprocidad mutua. Entonces, las relaciones sociales de larga duración hacen posible el surgimiento de la confianza, la reputación y la reciprocidad necesarias para la cooperación sostenida.

Las relaciones sociales duraderas, es decir, antiguas y con proyección en el largo plazo, son típicas entre aquellos que conforman comunidades relacionales, lo que tiene implicancias para la cooperación, la acción colectiva y la gobernanza. Las redes configuran en las comunidades dinámicas articuladas en torno a la cooperación que favorece el cumplimiento de compromisos, al desincentivar el oportunismo, lo cual hace posible la eficacia colectiva, la gobernanza comunitaria o el cumplimiento en comunidad, porque las relaciones cara a cara en vínculos cohesivos, multifacéticos, periódicos y públicamente reconocidos entre un número no muy alto de integrantes permiten el acceso de información sobre los integrantes de la red (sobre sus preferencias, competencias y comportamientos pasados) a bajo costo y, además, este alto grado de observabilidad multilateral, la larga duración de estas relaciones en un marco de derechos y de obligaciones compartidas favorecen la confianza y la reciprocidad, así como el interés de los individuos de invertir en reputación, ya que la coordinación de expectativas basada en creencias sobre compromisos creíbles formadas desde información local configura un contexto en el que es posible la cooperación condicional (Aoki, 2000; Barbera, 2005; Kandori, 1992).

Gracias a los aportes de la sociología económica, se dispone de los conceptos de fuerza del vínculo y multiplicidad del vínculo, que permiten precisar mejor las propiedades relacionales de las redes. Específicamente, la alta cohesión de las relaciones de comunidad relacional también fue analizada, desde la nueva sociología económica, por Granovetter $(1973,1982)$ en torno a lo que denominó «lazos fuertes», que se caracterizan por ser una combinación de intimidad, concebida como confianza mutua, además de tiempo, intensidad emocional y 
servicios recíprocos. En este mismo sentido, también aportan poder explicativo el embeddedness ('enraizamiento') relacional y el estructural (Granovetter, 1990, 1992). El enraizamiento relacional se refiere a que los «contratos implícitos», en donde las partes han demostrado que otorgan a las otras garantías y condiciones adecuadas en los intercambios que mantienen, se conforman en las relaciones sociales que tienen historia y continuidad y que se encuentran situadas en contextos sociales específicos. Además, las relaciones sociales son multifacéticas (múltiplex), porque los individuos se relacionan en más de un contexto social (parentesco, amistad, negocios, política, religioso, etc.) y la cooperación o no cooperación en un contexto afecta a las dinámicas en otro, por lo cual estos vínculos socialmente solapados operan como estructuras de governance informales, y no solo permean las interacciones cotidianas entre los individuos, sino también el funcionamiento de las organizaciones formales que integran.

En general, la relevancia del enraizamiento relacional se refiere al hecho de que la conducta de un individuo hacia otros depende de las expectativas mutuas que se han formado como parte constitutiva de las relaciones sociales. El enraizamiento estructural indica que las relaciones sociales se constituyen como redes cuya configuración tiene una estructura que incide en la naturaleza de las relaciones. De la estructura de relaciones depende, por ejemplo, el flujo de información en las redes: las que son más densas y que se conforman como grupos cohesivos facilitan el acceso más simétrico y rápido de información para sus integrantes. Esto tiene consecuencias para el control social informal, pues los grupos cohesivos son más eficientes en la generación de estructuras normativas, simbólicas y culturales que afectan a la conducta.

Las nociones de densidad, cierre de red, vinculos fuertes y vinculos múltiplex, así como de comunidad relacional, permiten entender, desde la perspectiva de las redes sociales, lo planteado por Bowles y Gintis (2002) sobre las relaciones de comunidad como el contexto que permite el papel del capital social para generar la gobernanza necesaria para la cooperación comunitaria.

A continuación, se analizará brevemente el papel de la estructura y de la naturaleza de los vínculos en la activación de la acción colectiva. En la teoría de redes sociales, Burt (2004) analizó la forma en que se producen las conexiones entre redes en torno a los agujeros estructurales, definidos como la ausencia de vínculos entre dos redes o secciones de una red desconectada, pero potencialmente vinculable. Esto es posible debido a los nodos situados al borde de estos agujeros, que, por su posición estructural estratégica, tienen la posibilidad de controlar recursos como la información en distintas regiones de la red, lo que permite que estas intercambien información entre sí.

Los nodos que tienen una alta capacidad de vincular subsecciones de la red destacan por su centralidad de intermediación, es decir, el grado en que constituyen un puente de paso para que otros nodos o subgrupos cohesionados, pero no conectados, se vinculen a través de él (Freeman, 2000). Los nodos con capacidad de intermediación son importantes, porque pueden controlar los flujos de información y, por esta razón, pueden ejercer el liderazgo necesario para la acción colectiva (Diani, 2003b). 
$\mathrm{Al}$ respecto, Hedström et al. (2000) presentan evidencia sobre la relevancia que tienen para la difusión territorial de movimientos sociales los agitadores que establecen vínculos con actores de diversos territorios, quienes, por su parte, se articulan en el interior de redes densas. En un contexto en el cual, para los actores territoriales, existe incertidumbre sobre las consecuencias futuras del movimiento social que se inicia, el contacto con un actor externo, que, actuando como un bróker, transporta información sobre el proceso de movilización desde un territorio hasta otro, gatilla que los actores de un territorio se sumen a la actividad política, lo que es provocado por dos mecanismos de influencia social combinados, que son la imitación (la observación de los resultados de la conducta de otro hace operar una heurística de aprendizaje, lo que conduce a una conducta similar) y la emulación (la interacción directa con otro persuade a actuar en la dirección propugnada por ese otro). Así, la información y la movilización política se difunden con creciente rapidez entre las redes y al interior de cada una de ellas.

$\mathrm{Al}$ revisar el papel de los intermediarios, desde la teoría del capital social, es posible comprender, para esta investigación, que las alianzas entre diversas redes pueden analizarse considerando la naturaleza de los vínculos que establecen entre sí las distintas personas de una red y los vínculos entre personas de distintas redes con otros actores. Las capacidades comunitarias expresadas en el capital social y las instituciones locales conforman un sistema territorial interactivo multicéntrico y autoorganizado, en el que participan integrantes de comunidades y organizaciones territoriales vinculados entre sí y con el Estado (Ostrom, 2010b). En este sentido, destacamos la propuesta de Evans (1997) sobre la sinergia entre Estado y sociedad, según la cual el Estado debe establecer vínculos cooperativos, complementando esfuerzos con las comunidades, con el fin de expandir sus capacidades. Posteriormente, Woolcok y Narayan (2000) proponen que, además de los vínculos de unión intracomunitarios (bonding), son necesarios los vínculos que conectan a las comunidades entre sí (bridging o vínculos de puente) y los vínculos de las comunidades con actores externos públicos y privados (linking o relaciones de conexión), lo cual permitiría a la comunidad acceder a recursos distintos a los que tienen, pudiendo resultar valiosos para sus propósitos. Este tipo de vínculos son llamados por Durston (2002) denomina «vínculos de escalera».

Cabe señalar, respecto a la naturaleza de los vínculos, que aquellos denominados «fuertes» son fundamentales para configurar estructuras de gobernanza, dado que permiten que se establezca una mayor confiabilidad entre las partes, lo cual hace posible la cooperación para la acción colectiva. Por su parte, los vínculos débiles, que habitualmente permiten tender puentes, son insuficientes, pues solo son útiles para realizar intercambios de baja complejidad y no se sustentan necesariamente en una fuerte confianza (Diani, 2011). Lo que se requiere, más bien, son alianzas interredes fundadas en vínculos densos y fuertes, desde los cuales logran realizar coordinaciones eficientes (Diani y Bison, 2004). 


\section{Metodología}

\subsection{Areas de estudio, población y muestra}

Concretamente, se trabajó en dos áreas de estudio de la región de La Araucanía ${ }^{2}$, cuyos deslindes fueron determinados según los límites de dos subcuencas, la primera de ellas denominada Trancura, ubicada en la cordillera de los Andes, que da origen al área de estudio de Curarrehue, y la segunda denominada Lumaco, que da origen al área de estudio del mismo nombre. Estas áreas de estudio abarcan una superficie de 236,222 y 66,145 hectáreas, respectivamente. En Lumaco, la escasez hídrica es muy importante, ya que se ubica en el secano interior de la región, donde las precipitaciones son escasas y la degradación de los recursos naturales es muy alta. En el área de Trancura, en cambio, las precipitaciones son más abundantes y los recursos naturales se encuentran en un mejor estado de conservación. La selección de estas dos áreas de estudio obedece a dos criterios principales, el primero de ellos es que presentan diferencias significativas sobre la disponibilidad de agua, pero en ambas existen problemas en el acceso al recurso, lo cual nos lleva al tema de los derechos hídricos y del aumento en la demanda por actividades productivas. El segundo criterio es el de conflictividad social. Ambas cuencas presentan la mayor cantidad posible de conflictos entre comunidades campesinas e indígenas con empresas privadas y el Estado. Lumaco tiene una larga historia de enfrentamientos entre comunidades indígenas y la expansión de las plantaciones forestales que son promovidas y financiadas por el Estado de Chile desde hace más de cincuenta años. Curarrehue es la comuna de la región que, en la última década, ha presentado la mayor cantidad de solicitudes para desarrollar proyectos productivos y extractivos que requieren de agua (instalación de seis centrales hidroeléctricas de pasada, alrededor de ocho pisciculturas y dos exploraciones mineras, además de la actividad turística de ríos y lagos), lo cual la ha convertido en la localidad con el mayor número de conflictos socioambientales de la región y del sur de Chile. Las dos áreas de estudio se presentan en la figura 1.

El área de estudio de Curarrehue se caracteriza por tener un clima templado, con una estación seca de cuatro meses y una cantidad anual de precipitaciones que fluctúa entre un mínimo de $910 \mathrm{~mm}$ y un máximo de $2.265 \mathrm{~mm}$ (Hijmans et al., 2005). Gran parte del territorio está ocupado por bosque nativo, solo el Parque Nacional Villarrica y la Reserva Nacional Villarrica ocupan el 74\% de la superficie. Dadas sus características morfológicas cordilleranas, hay un menor desarrollo de la agricultura, con un alto porcentaje de población

2. La región de La Araucanía posee un 23,4\% de población indígena mapuche, el porcentaje más alto del país y, además, sufre los índices de pobreza más elevados. Es la última región anexada al Estado Chileno, luego de lo que se denominó «Pacificación de la Araucanía» hacia finales del siglo XIx. Una de las estrategias que el Estado implementó para su sometimiento fue la ocupación por parte de colonos europeos, principalmente, alemanes, suizos, franceses e italianos, a los cuales se les concedieron tierras que hoy son reclamadas por el pueblo mapuche, lo que ha desencadenado, en las últimas décadas, variados conflictos entre los mapuches, el Estado y los colonos, así como la militarización de algunas comunas en donde se concentran los conflictos. 
Figura 1. Áreas de estudio

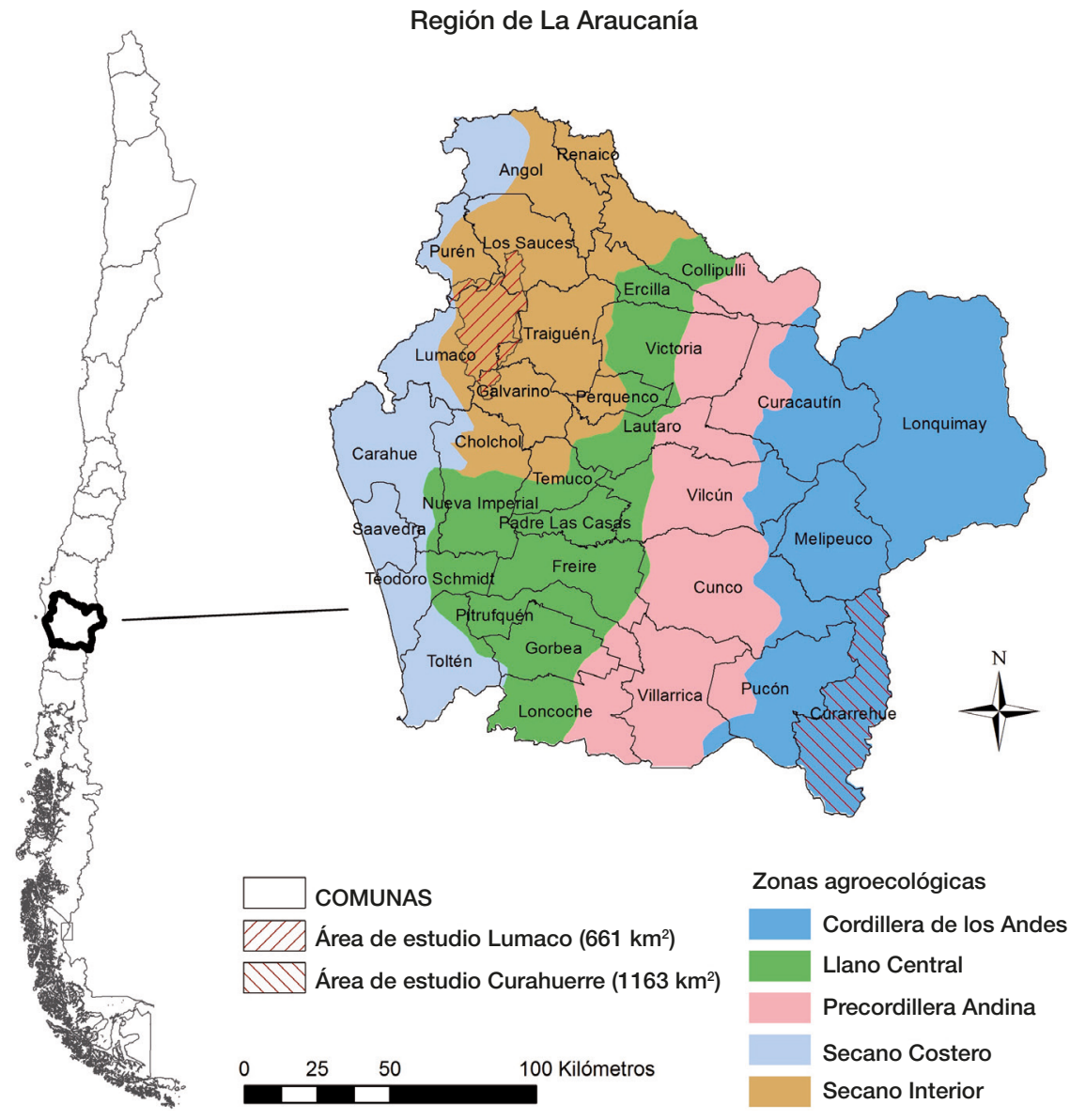

Fuente: elaboración propia.

rural $^{3}$ (un 72,5\%) y de población indígena - pehuenche y mapuche- (un $50,8 \%$ ) (INE, 2002). Curarrehue, en la última década, se ha transformado en un polo de atracción para el turismo de intereses especiales, dada su riqueza natural y cultural. Es una comuna productora de recursos hídricos, tanto por sus niveles de precipitaciones como por la nieve que se acumula en la alta cordillera. Pese a ello, son varias las localidades que, durante el verano, deben ser abastecidas de agua a través de camiones aljibes, principalmente por no contar con derechos hídricos ni con sistemas de distribución.

3. Para Chile, el porcentaje de población rural es de un 13,6\% aproximadamente, según el censo de población de 2002. 
El área de estudio de Lumaco se ubica en la zona agroecológica de secano interior (Rouanet et al., 1988), donde predomina un clima templado con una estación seca prolongada de seis meses. Anualmente, las precipitaciones fluctúan entre un mínimo de $918 \mathrm{~mm}$ y un máximo de $1.478 \mathrm{~mm}$ (Hijmans et al., 2005). Esta área presenta una degradación de los recursos naturales muy alta, principalmente por la pérdida de bosque nativo y su reemplazo por plantaciones exóticas. Es un área con un alto porcentaje de población rural (un $63,7 \%$ ), un $37,8 \%$ de la cual es población indígena mapuche (INE, 2002). La escasez hídrica es un problema desde hace varias décadas, situación que se ha profundizado en los últimos diez años, al coincidir con un período prolongado de sequía, que, sumado a los tipos de actividades productivas altamente demandantes de agua, hacen de esta área la más crítica de La Araucanía en temas de acceso y distribución del recurso.

La obtención de la muestra para las dos áreas de estudio se realizó en base a la subdivisión predial y no de familias o personas naturales. Se establecieron categorías de propiedades que fueron generadas en base a la unión de capas de información sobre "comunidades mapuche» (otorgada según el Título de Merced y Ley Indígena 19.253) y la inscripción de predios en el Servicio de Impuestos Internos (SII $)^{4}$. Luego de la unión, se generó una categoría denominada «tipo de propietario», la cual dio origen a tres tipos: «mapuche», "colono chileno" y "colono extranjero" 5 . La clasificación de predios permitió una doble proporcionalidad: 1) por el tipo de propiedad y 2) por área de estudio, tal como se muestra en las figuras 2 y 3 .

En función de la caracterización anterior, se obtiene un número total de predios para el área de Lumaco de 3.778 y para el área de Curarrehue, de 979, de lo cual deriva la muestra según el tipo de propietario y el área de estudio que se presenta en la tabla 1 .

4. Se trabaja con estas dos bases de datos, y no con el censo de población nacional, para identificar el tipo de propietario predial, dado que, en el censo, la pregunta por ser o no indígena no necesariamente se condice con lo que otras instituciones o programas del Estado considera como indígena, ello porque en el censo se pregunta "¿Quién se considera indígena?», lo cual no implica que declararse indígena implique, por ejemplo, que pueda ser objeto de programas de beneficios a pueblos originarios, como son las becas de estudio o la compra de tierras. Es por esta razón que se utilizan datos que se han construido con criterios que establece la Ley Indígena 19.253 para considerar a una persona como tal, esto es: ser hijos de padre o madre indígena, cualquiera que sea la naturaleza de su afiliación, inclusive la adoptiva, y ser cónyuge de una persona indígena.

5. En la investigación realizada, se decide por la categoría de colono descendiente de extranjero, dado que La Araucanía es una de las regiones en las que el Estado de Chile decide implementar un plan de ocupación del territorio a finales del siglo XIX y primeras décadas del siglo $\mathrm{xx}$, en consecuencia, son segundas o terceras generaciones las que habitan en los predios, principalmente, hablamos de descendientes de colonos alemanes, suizos, franceses e italianos, que legalmente son chilenos, pero que, dado el proceso de asignación de tierras por el Estado a los colonos y otros procesos hoy discutidos y cuestionados, son los que tienen las propiedades con mayor número de hectáreas y realizan una agricultura extensiva, a diferencia de los campesinos mapuches, que tienen predios pequeños, lo cual se puede apreciar claramente en las figuras 2 y 3 . 
Figura 2. Identificación de predios según el tipo de propietario. Área de estudio de Lumaco

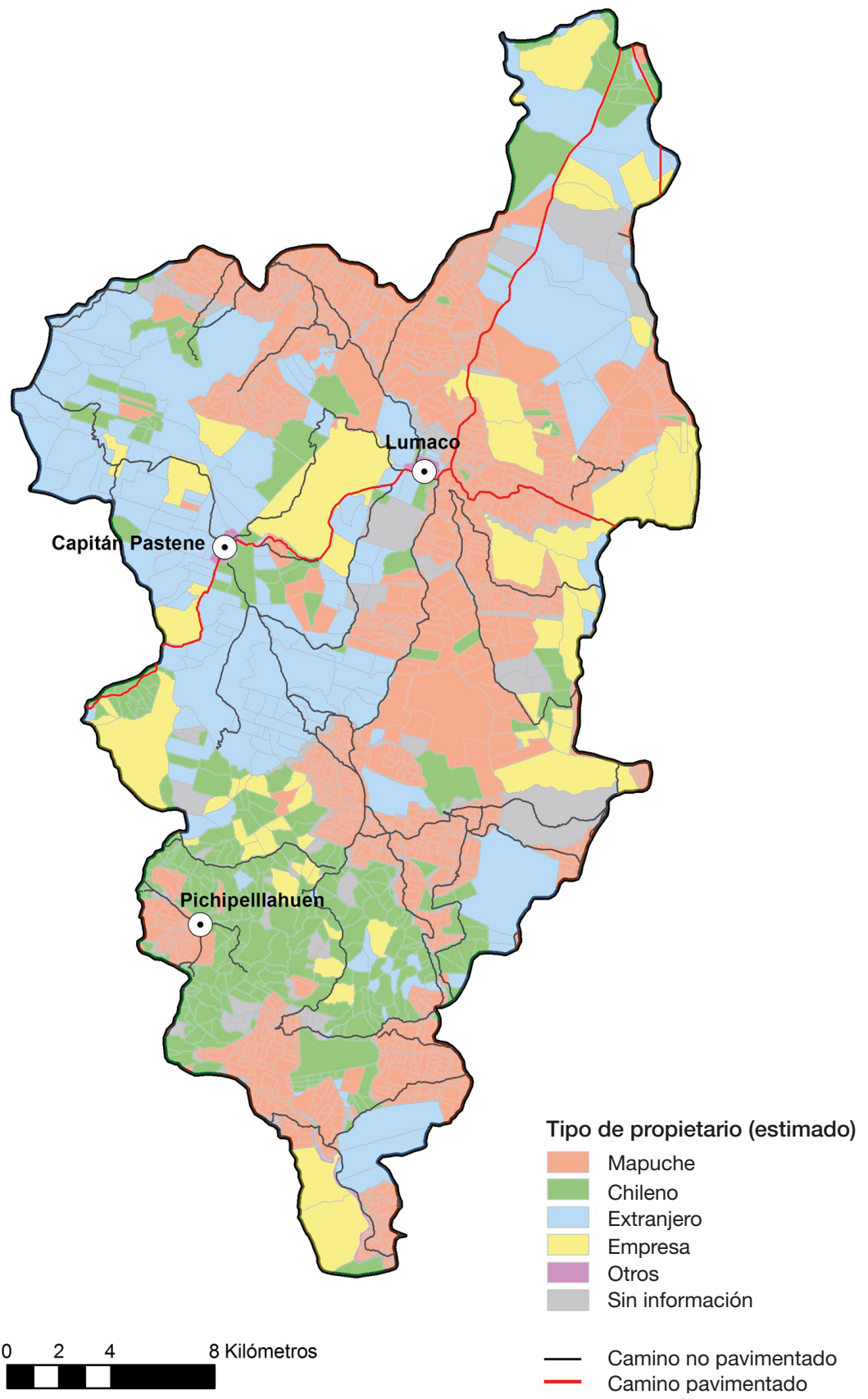

Fuente: elaboración propia. 
Figura 3. Identificación de predios según tipo de propietario. Área de estudio de Curarrehue

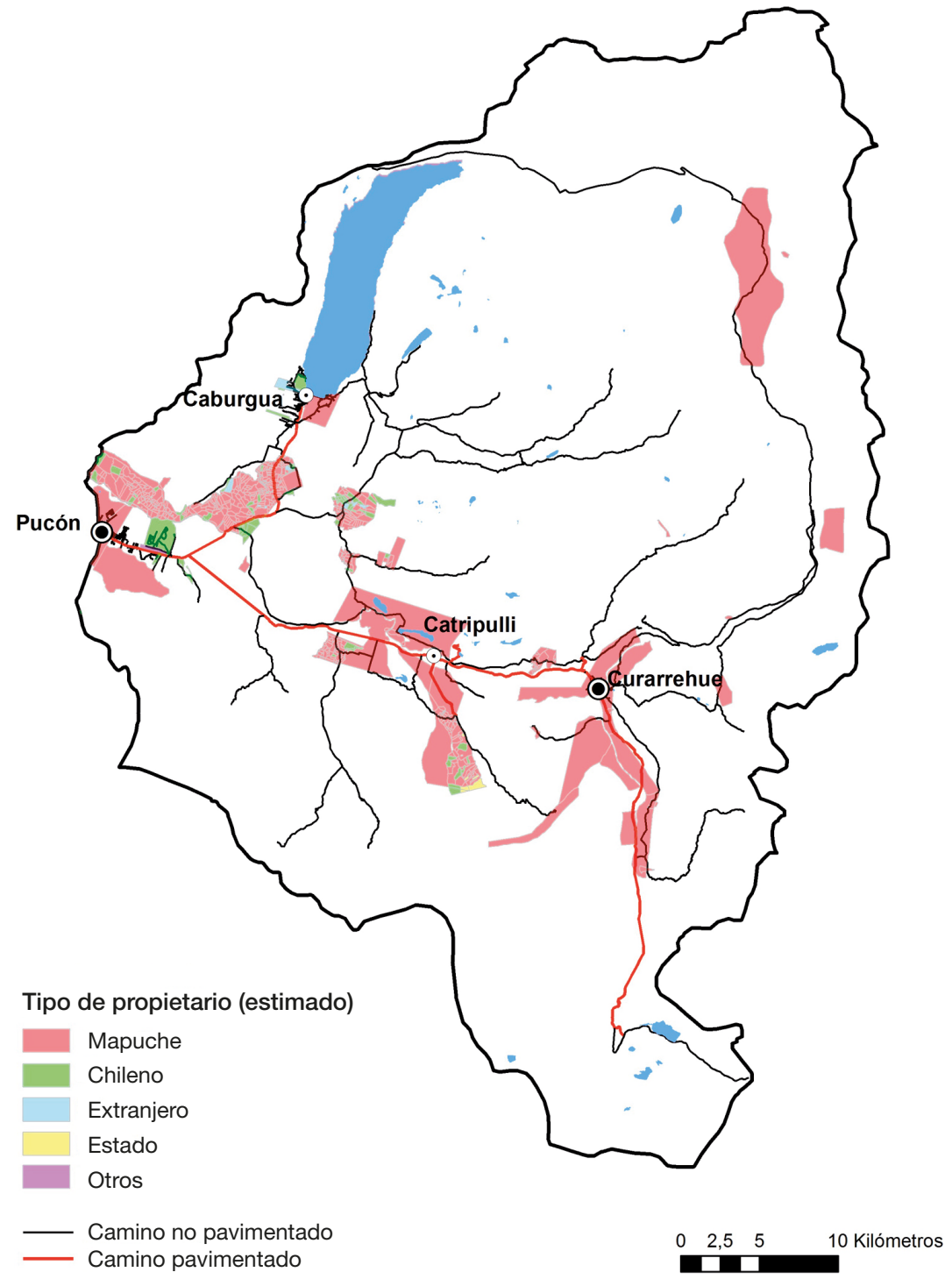

Fuente: elaboración propia. 
Tabla 1. Muestra de predios según el tipo de propietario por área de estudio

\begin{tabular}{lccc}
\hline Tipo de propiedad & Lumaco & Trancura & Total \\
\hline Mapuche & 131 & 39 & 170 \\
Chileno & 42 & 15 & 57 \\
Colono extranjero & 8 & 3 & 11 \\
\hline Total & 181 & 57 & 238 \\
\hline
\end{tabular}

\subsection{Técnicas y análisis}

Se aplicaron dos técnicas de recolección de información. La primera de ellas fue una encuesta que tuvo por objetivo describir la situación de acceso, distribución y uso del agua, y la segunda fue un cuestionario de redes sociales ${ }^{6}$, en el que se solicitó a las personas que indicaran con quiénes se relacionaban para solucionar problemas relativos al acceso al agua. Además, dicho cuestionario incluyó preguntas para establecer las propiedades estructurales y relacionales de las redes. Los instrumentos se aplicaron en espacios territoriales que, administrativamente, son identificados como localidades, para realizar un análisis de redes pertinente y acotado territorialmente, dada la amplitud geográfica de las áreas de estudio.

El análisis de redes se realizó considerando dos tipos de propiedades de estas. La primera es la propiedad estructural, para lo cual se centró la atención en su morfología, con el objetivo de determinar la forma en que se vinculan sus integrantes. Específicamente, se complementó el análisis de la estructura general de la red, a través de la densidad y el índice de centralización, con el análisis de conjuntos de relaciones y subgrupos (relaciones diádicas, triádicas y cliques) y con el análisis posicional o locacional, situado en torno a la centralidad de grado y de intermediación. Para el procesamiento de datos, se utilizó UCINET 6, a través del cual se obtuvieron los valores de las medidas señaladas, y Netdraw, para elaborar representaciones gráficas de las redes estudiadas.

Para el segundo tipo de análisis, referido a las propiedades relacionales, específicamente, a la naturaleza de las relaciones, se consideraron los vínculos que las personas han establecido, la antigüedad de los mismos, la frecuencia, el grado de confianza, el contexto social de la relación (simple, multifacético o múltiplex), la expectativa de continuidad de la relación en el futuro y la existencia de relaciones de conexión o vínculos de escalera. Estos datos fueron procesados descriptivamente a través de valores porcentuales.

\section{Resultados}

Los datos que se expondrán a continuación constituyen la evidencia empírica desde la cual se analizaron las condiciones requeridas para el surgimiento de la

6. Sobre la metodología de análisis de redes, se tuvo como referencia a Carrington et al. (2005), Kadushin (2013), Streeter y Gillespie (1992) y Wasserman y Faust (2013). 
acción colectiva en las áreas de estudio, que permitirían enfrentar problemas vinculados con el acceso a agua. La presentación y el análisis de los datos se estructurará considerando los antecedentes presentados sobre capital social, redes sociales y acción colectiva. Específicamente, se realizó, primero, un análisis sobre las redes sociales entre personas de las localidades de las áreas de estudio y, segundo, entre personas de las localidades con actores externos a ellas pero pertenecientes al área de estudio. Sobre cada una de estas redes, se analizaron sus propiedades estructurales y relacionales.

\subsection{Red entre personas en las localidades de las áreas de estudio}

Se comenzará analizando las propiedades estructurales de las redes sociales entre personas de las localidades. Según los antecedentes teóricos, los vínculos que establecen las personas les permiten acceder a recursos de capital social, específicamente, reciprocidad e información. Esta última es clave para conocer la disposición que existiría para cooperar por parte de los otros, lo que, a su vez, serviría para la formación de confianza y el funcionamiento de las normas sociales.

\subsubsection{Propiedades estructurales de la red entre personas de las localidades del área de estudio de Curarrehue}

Para el análisis de las propiedades estructurales, en primer lugar, se hará referencia a la densidad, que, como señalamos, es una medida de cohesión global de la red y que expresa la proporción entre los vínculos posibles y los vínculos existentes. La red tiene una densidad muy baja, con un valor de 0,0120 , lo que indica la escasa vinculación global entre las personas. De hecho, en relación con los conjuntos de relaciones en la red, destacamos que el 12,94\% tiene tres o más vínculos y que el $12,94 \%$ no tiene ninguno. Tampoco existe una alta vinculación local en la red, dado que solo se identifican cuatro cliques (clique SL, IC28, AC44; clique IC28, ML42, A44; clique AC44, AC, ML42, y clique A44, ML42, EL), compuestos por tres personas directamente vinculadas entre sí y que son destacados en la figura 3. Al interior de estos cliques, existe una alta cohesión, porque las personas integran más de uno, por lo cual estos, ubicados territorialmente en la localidad de Trancura, son solapados o entrecruzados. La baja conectividad local y la baja concentración de vínculos también da cuenta de una red que no tiene una estructura jerárquica, puesto que, en efecto, el índice de centralización es un 4,80\%. Además, respecto al análisis locacional o posicional, hay muy pocas personas relevantes por su centralidad de intermediación, y la mayoría solo intermedia en el interior de las redes egocentradas que integra, que sí tienen una estructura jerárquica y en cuyo interior sí destacan por su centralidad de grado (por ejemplo: EB29, IC52 y AO09, ver figura 3). No obstante, estas subredes están desconectadas del resto y no se identifican personas que «tiendan puentes» entre subredes y, al respecto, solo destaca FR47, resaltado en la figura 4, quien tiene una posición de intermediación entre personas que, territorialmente, viven en distintas loca- 
Figura 4. Red entre personas de las localidades del área de estudio de Curarrehue

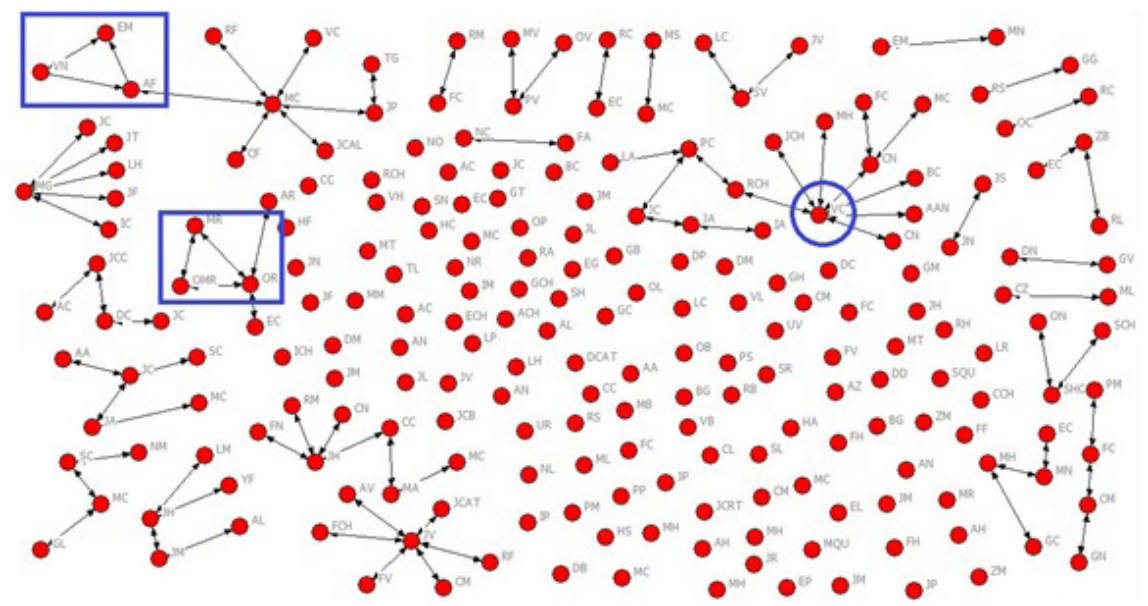

Fuente: elaboración propia.

lidades en el área de estudio de Curarrehue, específicamente, en las localidades de Catripulli y Loncofilo.

\subsubsection{Propiedades estructurales de la red entre personas de las localidades del área de estudio de Lumaco}

En primer lugar, la densidad de la red es muy baja y alcanza un 0,0034 , lo que expresa una cohesión o conectividad global muy reducida. Esto es coherente con los datos sobre los conjuntos de relaciones: de un total de 238 personas, un $4,54 \%$ tiene tres o más vínculos; un 10,9\% tiene 2 vínculos; un $25,9 \%$ tiene 1 vínculo, y un $57,27 \%$ no tiene vínculos. Además, la red se caracteriza por la baja conectividad local, pues solo se identifican dos cliques (clique VN, AF, EM y clique MR, OR, OMR), destacados en la figura 5. En complemento, la red no tiene una estructura global jerárquica, ya que el índice de centralización es de 2,86. Por último, solo VC (destacado en la figura 5) tiene una posición comparativamente importante, pero su posición de intermediador únicamente opera en la subred que integra.

\subsubsection{Propiedades relacionales de la red entre personas de las localidades del área de estudio de Curarrehue}

Para analizar las redes sociales como estructuras sociales que pueden favorecer la formación de capital social, además de revisar sus propiedades estructurales, es necesario examinar sus propiedades relacionales, específicamente referidas a la naturaleza de los vínculos que establecen las personas. Al tratar el concepto de comunidad relacional, la combinación entre las propiedades estructurales $\mathrm{y}$ relacionales produce determinadas condiciones que hacen posible el surgi- 
Figura 5. Red entre personas de las localidades del área de estudio de Lumaco

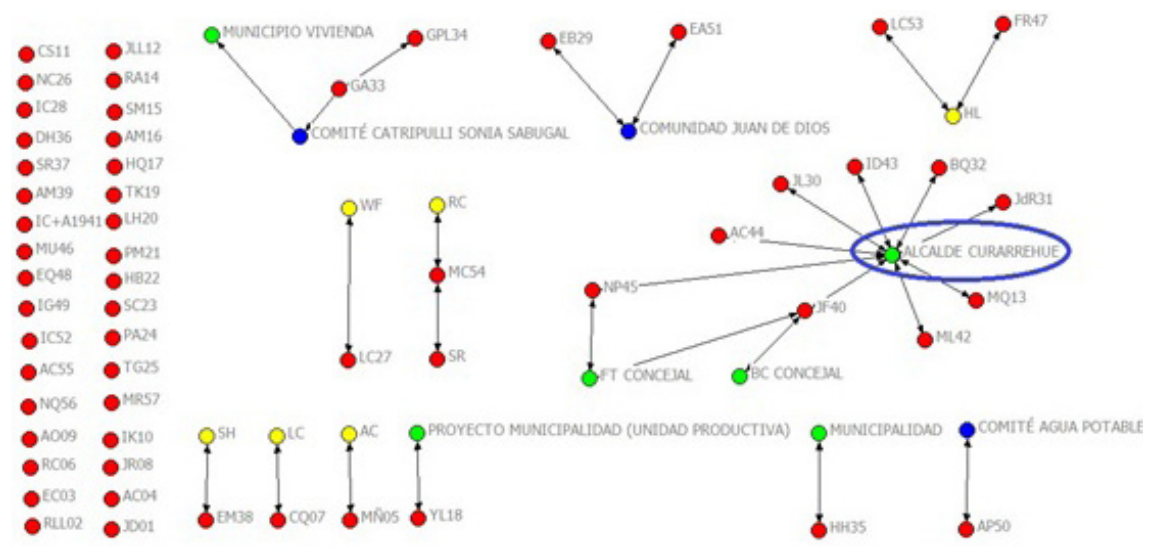

Fuente: elaboración propia.

miento de la confianza, la reciprocidad y las normas sociales necesarias para la cooperación. Entonces, respecto a la naturaleza del vínculo, la atención se centra en la fuerza de este, expresada en la antigüedad de la relación, la frecuencia de la interacción y el grado de confianza implicado. Además, se observa si el vínculo es simple o multifacético, es decir, si está situado en uno o en varios contextos sociales, así como la expectativa de las personas sobre la continuidad de la relación en el futuro.

En referencia a la fuerza de los vínculos, se pueden calificar de fuertes. Las relaciones sociales son de largo tiempo (un 96\% de los encuestados señala que conoce a las personas desde hace más de 10 años), de interacción frecuente (un $32 \%$ de las personas señala que se produce diariamente y un 39\%, una vez a la semana) y de mucha confianza (un $83 \%$ confía mucho en la persona con la que establece la relación). Los vínculos muestran una alta proyección (un 97\% de las personas tiene la expectativa de que la relación continuará en el futuro) y se producen en contextos sociales de proximidad (un $49 \%$ de ellas son de parentesco). En complemento, un $86 \%$ de las personas reporta que otorga importancia a las opiniones de los otros y un $84 \%$ considera que los otros dan importancia a sus opiniones. Además, un $93 \%$ de los encuestados señala que las relaciones con los otros son de cooperación.

\subsubsection{Propiedades relacionales de la red entre personas de las localidades del área de estudio de Lumaco}

En relación con esta red, los vínculos se pueden calificar de fuertes. Las relaciones sociales son de larga data (un $90 \%$ señala conocer a sus contactos desde hace más de 10 años), de interacción frecuente (un 31\% indica verse diariamente y un $27 \%$, una vez a la semana) y de mucha confianza (un $85 \%$ reporta confiar mucho en contactos). Además, los vínculos tienen proyección (un 99\% 
señala creer que seguirá relacionándose con esas personas en el futuro) y se producen en contextos sociales de proximidad (un 67\% de las relaciones son de parentesco). Sobre el grado de influencia de los vínculos, un $82 \%$ indica que otorga importancia a las opiniones de otros y un $84 \%$ estima que los otros conceden importancia a sus opiniones. Finalmente, es destacable que un 100\% de los encuestados califica las relaciones que establece como cooperativas.

\subsection{Red entre personas de una localidad con actores del área de estudio}

En complemento al análisis sobre las redes entre las personas de una misma localidad, se presentan las redes entre gente de las localidades con actores del área de estudio que pudieran tener injerencia en la solución de problemas de acceso al agua. Este tipo de red interesa, porque permite visualizar si las personas disponen de relaciones de conexión o vínculos de escalera, que hacen posible la existencia de alianzas que pueden promover el empoderamiento. Las redes de ambas áreas de estudio se analizaron considerando su estructura y su tipo de vínculos.

\subsubsection{Propiedades estructurales de la red entre personas de una localidad con actores del área de estudio de Curarrehue}

La primera característica de la estructura de esta red es su muy baja cohesión global y local, pues, por una parte, su densidad es de 0,0095 , lo que da cuenta de una muy baja vinculación entre las personas de las localidades del área de estudio. Efectivamente, de un total de 74 encuestados, hay solo un actor, que representa un 1,36\%, con más de tres vínculos, 7 actores tienen relaciones diádicas, 27 tiene un vínculo y 39 no tiene vínculos, lo cual representa el 52,70\% del total. Por otra parte, en relación con la cohesión local, no existen cliques. La segunda característica de la red es que absolutamente no tiene una estructura jerárquica, ya que su índice de centralización es de un 7,39\%. La tercera característica de la red es que el análisis locacional o posicional evidencia que no existen integrantes altamente relevantes por su posición central, ya sea por su centralidad de grado o de intermediación. Únicamente destaca por su centralidad de grado el alcalde de Curarrehue (identificado en la figura 6), que tiene una centralidad de grado 9 (él es el único integrante de la red con más de tres vínculos, según lo antes señalado) y la más alta centralidad de intermediación. Este integrante de la red es el jefe del gobierno local, es decir, del municipio, que es la organización del Estado con presencia en el área de estudio con la cual sus habitantes establecen comparativamente más vínculos. Otros integrantes de la red que forman parte del municipio, que son destacados en la figura 6 como nodos de color verde, son departamentos de desarrollo, como el de vivienda y el de fomento productivo, y dos concejales. Además, los habitantes del área de estudio tienen vínculos, que también se pueden calificar como relaciones de conexión o vínculos de escalera, con organizaciones territoriales (nodos de color azul) y con personas del territorio, dedicadas a actividades fundamentalmente ambientalistas (nodos de color amarillo). 
Figura 6. Red entre personas de una localidad con actores de otras localidades del área de estudio de Curarrehue

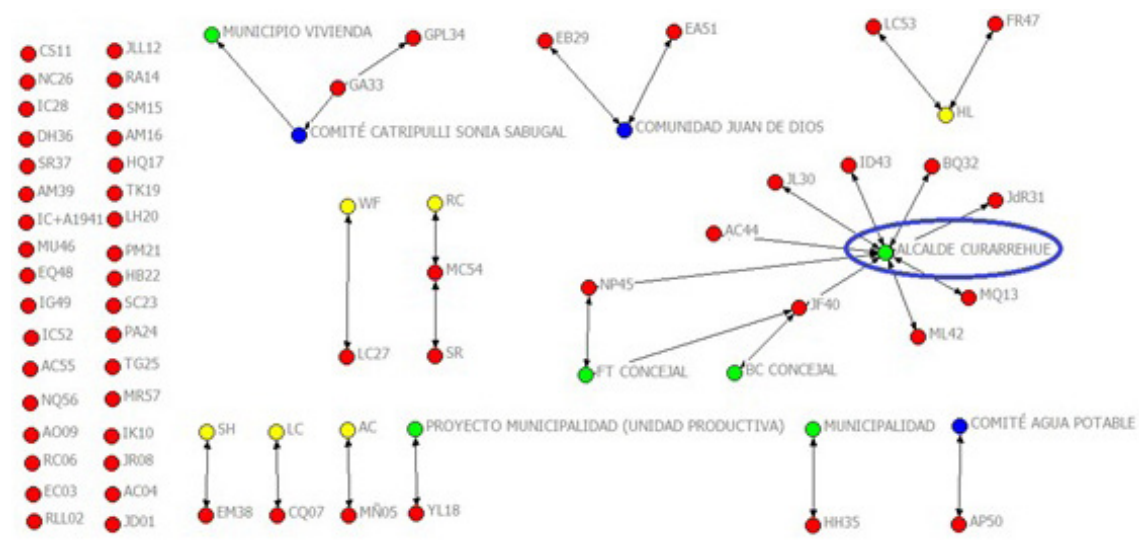

Fuente: elaboración propia.

\subsubsection{Propiedades estructurales de la red entre personas de una localidad con actores del área de estudio de Lumaco}

La red de vínculos entre habitantes de localidades del área de estudio de Lumaco tiene una estructura con muy baja cohesión global, pues su densidad es de 0,0011. De un total de 193 personas, solo 3 (un 1,55\% del total) tienen 3 o más vínculos, 4 muestran relaciones diádicas, 21 tienen 1 vínculo y 165 (un $85,4 \%$ del total) no tiene vínculos con otros. Además, no existe cohesión local, porque no se detectan cliques. Aparte de su baja cohesión, la red no tiene una estructura jerárquica, ya que su índice de centralización es de un 2,50\%. En relación con la centralidad de intermediación en la red, hay dos integrantes que presentan mayor capacidad para vincular a otros no directamente vinculados. Uno de ellos es una organización territorial, el comité Arcoiris, que se trata de una de las tres entidades comunitarias (nodos de color azul en la figura 7) con las que los habitantes del área de estudio establecen vínculos, aunque, claro está, son muy pocos. En todo caso, la capacidad de intermediación incluye un radio limitado de alcance hacia muy pocos nodos. Finalmente, se señala que solo dos habitantes establecen vínculos con representantes del municipio, destacados como nodos verdes. Se trata del alcalde de Traiguén y un departamento municipal (PRODESAL).

\subsubsection{Propiedades relacionales de la red entre personas de una localidad con actores del área de estudio de Curarrehue}

Respecto a la naturaleza del vínculo establecido entre personas de las localidades con otras personas del área de estudio, se puede calificar de fuerte. Las relaciones sociales son de larga duración (un 58\% señala conocer a los otros 
Figura 7. Red entre personas de una localidad con actores de otras localidades del área de estudio de Lumaco

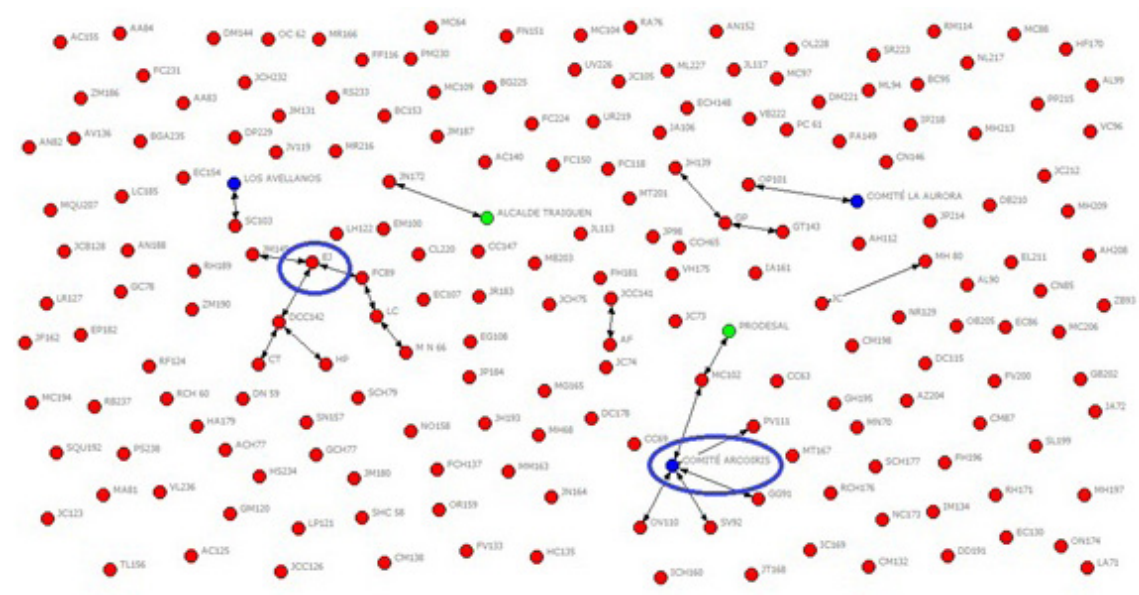

Fuente: elaboración propia.

con quienes se vincula hace más de 10 años y un 19\%, entre 5 y 10 años), de interacciones muy frecuentes (un 23\% indica verse una vez a la semana y un $62 \%$, al menos una vez al mes) y de mucha confianza (un $88 \%$ señala confiar mucho en los otros). Los vínculos tienen proyección en el tiempo (un $92 \%$ señala que seguirá relacionándose con las personas en el futuro) y son de cooperación (un 92\%). Por último, otro elemento que da cuenta de la fortaleza del vínculo es que el $88 \%$ de las personas plantea que sus opiniones son tomadas en cuenta y el mismo porcentaje considera que toma en cuenta las opiniones de los otros.

\subsubsection{Propiedades estructurales de la red entre personas de una localidad con actores del área de estudio de Lumaco}

Respecto a la naturaleza del vínculo establecido entre personas de las localidades con otras del área de estudio de Lumaco, se puede considerar fuerte. Las relaciones sociales son de larga duración (un 37\% señala conocer a los otros con quienes se vincula hace más de 10 años y un 19\%, entre 5 y 10 años), de interacción frecuente (un $81 \%$ indica verse al menos una vez al mes) y de mucha confianza (un 70\% señala confiar mucho en los otros). Los vínculos tienen proyección en el tiempo (un 100\% señala creer que seguirá relacionándose con las personas en el futuro) y de cooperación (un 96\% los califica así). Por último, el $74 \%$ declara que sus opiniones son tomadas en cuenta y un $81 \%$ plantea que toma en cuenta las opiniones de los otros. A continuación, se presentan dos tablas que sintetizan las propiedades estructurales y relacionales de las redes sociales. 
Tabla 2. Síntesis de propiedades estructurales de las redes en las áreas de estudio de Curarrehue y Lumaco

\begin{tabular}{|c|c|c|c|c|c|c|c|}
\hline \multirow[b]{2}{*}{ Red } & \multirow[b]{2}{*}{ Comuna } & \multirow[b]{2}{*}{$\begin{array}{c}\mathrm{N} . .^{\circ} \\
\text { nodos }\end{array}$} & \multicolumn{5}{|c|}{ Propiedades estructurales } \\
\hline & & & Densidad & $\begin{array}{c}\text { Índice de } \\
\text { centralización }\end{array}$ & $\begin{array}{l}\mathrm{N} .^{\circ} \\
\text { cliques }\end{array}$ & $\begin{array}{l}\text { Porcentaje } \\
\text { de nodos con } \\
\text { tres o más } \\
\text { vínculos }\end{array}$ & $\begin{array}{l}\text { Porcentaje } \\
\text { de nodos sin } \\
\text { vínculos }\end{array}$ \\
\hline \multirow{2}{*}{$\begin{array}{l}\text { Red de personas } \\
\text { de la localidad }\end{array}$} & Curarrehue & 139 & 0,0120 & $4,80 \%$ & 4 & $12,94 \%$ & $12,94 \%$ \\
\hline & Lumaco & 220 & 0,0034 & $2,86 \%$ & 2 & $4,54 \%$ & $52,27 \%$ \\
\hline \multirow{2}{*}{$\begin{array}{l}\text { Red de personas de } \\
\text { las localidades con } \\
\text { actores externos }\end{array}$} & Curarrehue & 74 & 0,0095 & $7,93 \%$ & 0 & $1,36 \%$ & $52,70 \%$ \\
\hline & Lumaco & 193 & 0,0011 & $2,50 \%$ & 0 & $1,55 \%$ & $85,4 \%$ \\
\hline
\end{tabular}

Fuente: elaboración propia.

Tabla 3. Síntesis de las propiedades relacionales de las redes en las áreas de estudio de Curarrehue y Lumaco

\begin{tabular}{|c|c|c|c|c|c|c|c|}
\hline \multirow[b]{2}{*}{ Red } & \multirow[b]{2}{*}{ Comuna } & \multirow[b]{2}{*}{$\begin{array}{c}\mathrm{N} .{ }^{\circ} \\
\text { nodos }\end{array}$} & \multicolumn{5}{|c|}{ Propiedades relacionales } \\
\hline & & & $\begin{array}{l}\text { Antigüedad del } \\
\text { vínculo }\end{array}$ & $\begin{array}{l}\text { Frecuencia de } \\
\text { interacción }\end{array}$ & $\begin{array}{l}\text { Nivel de } \\
\text { confianza }\end{array}$ & $\begin{array}{c}\text { Expectativa } \\
\text { de relación } \\
\text { en futuro }\end{array}$ & $\begin{array}{l}\text { Contexto } \\
\text { del vínculo }\end{array}$ \\
\hline \multirow[t]{2}{*}{$\begin{array}{l}\text { Red personas } \\
\text { localidad }\end{array}$} & Curarrehue & 220 & $\begin{array}{l}\text { Más de } 10 \text { años: } \\
96 \%\end{array}$ & $\begin{array}{l}\text { Diaria: } 32 \% \\
\text { Semanal: } 39 \%\end{array}$ & $\begin{array}{l}\text { Mucha confianza: } \\
83 \%\end{array}$ & $97 \%$ & $\begin{array}{l}\text { Parentesco: } \\
49 \%\end{array}$ \\
\hline & Lumaco & 139 & $\begin{array}{l}\text { Más de } 10 \text { años: } \\
90 \%\end{array}$ & $\begin{array}{l}\text { Diaria: } 31 \% \\
\text { Semanal: } 27 \%\end{array}$ & $\begin{array}{l}\text { Mucha confianza: } \\
85 \%\end{array}$ & $99 \%$ & $\begin{array}{l}\text { Parentesco: } \\
67 \%\end{array}$ \\
\hline \multirow[t]{2}{*}{$\begin{array}{l}\text { Red personas } \\
\text { localidades con } \\
\text { actores externos }\end{array}$} & Curarrehue & 193 & $\begin{array}{l}\text { Más de } 10 \text { años: } \\
58 \% \\
5 \text { a } 10 \text { años: } \\
19 \%\end{array}$ & $\begin{array}{l}\text { Semanal: } 23 \% \\
\text { Mensual: } 62 \%\end{array}$ & $\begin{array}{l}\text { Mucha confianza: } \\
88 \%\end{array}$ & $92 \%$ & \\
\hline & Lumaco & 74 & $\begin{array}{l}\text { Más de } 10 \text { años: } \\
37 \% \\
5 \text { a } 10 \text { años: } \\
19 \%\end{array}$ & Mensual: $81 \%$ & $\begin{array}{l}\text { Mucha confianza: } \\
70 \%\end{array}$ & $100 \%$ & \\
\hline
\end{tabular}

Fuente: elaboración propia.

\subsection{Participación en organizaciones locales y de las áreas de estudio}

Según lo planteado en los antecedentes teóricos, específicamente en lo referido a organización social apropiable, la existencia de organizaciones locales permite la generación de capital social que puede utilizarse para abordar problemáticas compartidas, es decir, la participación en algún tipo de organización implica un aprendizaje social en la cooperación, que puede ser utilizado en otras situaciones o problemáticas. En función de lo anterior, se consideró relevante conocer la participación de las personas de ambas áreas de estudio en distintos tipos de organizaciones.

Los resultados obtenidos muestran que, en el área de estudio de Curarrehue, un 50\% de los encuestados plantea que la principal organización es la 
«comunidad indígena tradicional», que tiene como objetivos la defensa de la cultura y del pueblo mapuches. Un $61 \%$ de las personas señala que conoce la existencia de algún tipo de organización que aborda el tema del agua, mientras que solo un 12,32\% dice participar en otro tipo de organizaciones, en las que encuentran algunas que tratan el tema del agua. En el caso del área de estudio de Lumaco, un $77,3 \%$ designa a la "comunidad indígena tradicional» como la organización más relevante, un $72,5 \%$ no identifica, en el área de estudio, la existencia de algún tipo de organización que trabaje el tema del agua y, por último, un $79,5 \%$ declara no participar en organizaciones que consideren el tema del agua como central.

Una vez presentada la descripción de los datos sobre las propiedades estructurales y relacionales de las redes sociales de las áreas de estudio, a continuación, se expone un breve análisis, considerando para ello los contenidos de la sección sobre antecedentes teóricos y el objetivo de la investigación realizada, que, como se indicó, fue analizar las condiciones necesarias, asociadas a las redes sociales y al capital social, para el surgimiento de la acción colectiva de campesinos para enfrentar problemas relacionados con el acceso al agua. Si los antecedentes teóricos se refirieron al capital social y a las redes sociales, entonces, la acción colectiva se activará siempre que existan propiedades relacionales y estructurales en las redes. Es decir, si las redes tienen suficiente cierre o existen suficientes cliques solapados y vinculados entre sí a través de nodos con alta capacidad de intermediación, o si la red es altamente centralizada o jerárquica y se activan los nodos que concentran vínculos y que tienen una alta centralidad de grado, la información circulará suficientemente para producir la necesaria coordinación y cooperación al interior de las redes y entre las redes, y, respecto a estas últimas, podrán operar las relaciones de conexión o los vínculos de escalera. También aportará la existencia de vínculos fuertes y la participación de las personas en organizaciones, y todo lo anterior, desde una perspectiva más general, viabilizará la generación de los procesos intrarredes e interredes.

$\mathrm{Al}$ analizar los datos disponibles, se puede afirmar que las redes estudiadas son, en términos generales, similares en sus propiedades estructurales. En todas se observa una baja cohesión global y local, dada la muy mínima densidad y los escasos cliques identificados, lo que significa que no existen suficientes canales para que circule la información entre todas las personas. Lo mismo ocurre con las limitadas posibilidades de transmisión de información entre habitantes de una misma localidad, entre habitantes de diferentes localidades y entre estos y personas y organizaciones con presencia en las áreas de estudio. En todas las redes, sus integrantes establecen muy pocos vínculos entre sí. Solo son observables conexiones entre gente que habita un espacio territorial muy próximo y que, además, son bidireccionales o concentradas en torno a un individuo. Cabe señalar que quienes tienen más alta centralidad de grado, pueden acceder y distribuir recursos como la información desde y hacia las personas con las que se vinculan. Pero estas personas más vinculadas, que, a su vez, tienen, comparativamente, más centralidad de intermediación, solo 
operan como nexos al interior de sus subredes, que están desconectadas del resto, lo que dificulta la viabilidad de acciones cooperativas entre actores de distintas localidades (vínculos de puente) y también con otros actores de las áreas de estudio (relaciones de conexión o vínculos de escalera) para solucionar problemas referidos al agua.

Lo anterior configura un panorama, en principio, desalentador respecto a las condiciones para la emergencia de la acción colectiva. No obstante, el análisis sobre las propiedades relacionales evidencia que los vínculos son de naturaleza fuerte, lo que expresa, promisoriamente, que existen propiedades relacionales de las redes que favorecerían la cooperación. Sin embargo, esta cooperación se encontraría restringida o encapsulada en las relaciones bidireccionales y en el interior de los escasos cliques situados en contextos espaciales muy reducidos. Es decir, en términos de Durston (2002), se trataría básicamente de un capital social individual, que circula en las redes egocentradas, y de un capital grupal, que se articula desde el entretejimiento de las redes egocentradas.

En las dos áreas de estudio y en relación con la participación en organizaciones, los resultados evidencian la escasa presencia de las que tienen como preocupación central los temas relativos al agua. Más aún, la participación en este modelo de organizaciones es muy reducida y se produce en otro tipo distinto de ellas, como la comunidad indígena tradicional, que tiene una historia en los territorios y que obedece a lógicas organizacionales comunitarias e identitarias que no se rigen por las estructuras de las administraciones funcionales chilenas. Si bien las asociaciones en torno al agua no son las más importantes, el hecho de que existan algunas de otro tipo permite plantear que hay un aprendizaje organizacional que se podría activar potencialmente, considerando los efectos virtuosos de la organización social apropiable, para crear otros grupos o asumir los temas del agua como problemas comunitarios de importancia para el bienestar colectivo de las localidades.

\section{Conclusiones}

En torno a las condiciones para la emergencia de la acción común, la debilidad evidenciada respecto a las propiedades estructurales de las redes existentes (baja densidad, escasez de cliques y de nodos que conecten) limita las posibilidades actuales para que en las áreas de estudio se emprendan acciones colectivas tendentes a solucionar problemas de acceso al agua y gestionar un recurso escaso y que opera como un bien privado. No obstante, la existencia de lazos fuertes entre las personas de una misma localidad permitiría plantear que existen condiciones relacionales incipientes que deben ser ampliadas, para lo cual se requiere modificar la estructura global de las redes, es decir, que logren establecerse vínculos entre distintas localidades y a nivel de las áreas de estudio, es decir, de la cuenca territorial en que se emplazan. Esto es necesario si se pretende minimizar los riesgos de escasos y posibles conflictos sociales, gestionando el recurso de forma integral y dando soluciones a los problemas de acceso, distribución y cuidado del agua. Esto supone la necesidad de intervenir 
en las redes sociales de las áreas de estudio desde un enfoque de gobernanza territorial, para lo cual podrían tener un rol protagónico los municipios presentes en ambas, que son con quienes más se vinculan las personas. En todo caso, el efecto catalizador de los municipios será tal si, como lo prescribe la literatura especializada, se orientan desde una lógica de buen gobierno, no incurriendo en prácticas clientelares, que resultan perjudiciales para sustentar el desarrollo en el largo plazo.

En las áreas de estudio, era esperable observar un desarrollo más articulado de los territorios en base a redes y organizaciones que les permitiera afrontar colectivamente los problemas de acceso al agua, sobre todo teniendo en cuenta que estos problemas no se deben solo a la escasez del recurso, sino también al acceso limitado, porque la mayoría de las personas no cuentan con derechos hídricos. Por ende, la existencia de organizaciones y redes capaces de articular contenciosamente las demandas sobre el recurso era particularmente esperable en el área de estudio de Lumaco, dada su historia social y política, donde las organizaciones comunitarias y mapuches han logrado posicionar temas reivindicativos en relación con la recuperación de los territorios entendidos como indígenas, capacidades que — en función de la información obtenida en esta investigación - no se pueden extrapolar, por ejemplo, a acciones tendientes a la recuperación de derechos de agua.

Lo anterior se podría explicar porque, solo durante los últimos diez años, el agua se ha transformado en un problema y en una fuente de conflictos sociales en La Araucanía. Con la disminución de las precipitaciones y la existencia de una estación seca más prolongada (posiblemente vinculadas a transformaciones producidas por los cambios ambientales globales), las familias campesinas, acostumbradas a utilizar agua de lluvia, necesariamente han tenido que acceder a otros sistemas de abastecimiento hídrico para el desarrollo de la agricultura campesina, recursos que hoy están en manos de empresas privadas y de grandes propietarios agrícolas.

En el caso de Curarrehue, si bien es un territorio productor de agua, existe una alta demanda del recurso y una alta concentración de los derechos de líquido elemento (pisciculturas, hidroeléctricas, mineras y empresas relacionadas con el turismo), por lo cual era razonable esperar la existencia de algún tipo de organización para la defensa del recurso, pero, al igual que en Lumaco, no hay organizaciones que hayan surgido a partir del interés comunitario por la defensa del agua, que enfrenten el dominio que tienen las empresas sobre los derechos hídricos en la cuenca.

La inexistencia de acción colectiva en ambas áreas de estudio tiene una explicación más profunda, que se encuentra en el modelo económico chileno, altamente privatizador de los recursos naturales, en donde los actores privados y, particularmente, la empresa privada son considerados los más adecuados para explotarlos, asignarlos, gestionarlos y distribuirlos eficientemente. Lo anterior ha ido en paralelo a una desvalorización de las organizaciones locales del Estado (municipio) y de las capacidades de las organizaciones comunitarias para gestionar los recursos naturales que encuentran en sus territorios. 


\section{Referencias bibliográficas}

Ahn, Toh-Kyeong y Ostrom, Elinor (2008). «Social capital and collective action». En: Castiglione, D.; Van Deth, D. y Wolleb, G. (eds.). Handbook of Social Capital. Oxford: Oxford University Press.

Anand, Prathivadi (2007). «Capability, Sustainability, and Collective Action: An Examination of a River Water Dispute». Journal of Human Development [en línea], 8 (1), 109-132. <http://dx.doi.org/10.1080/14649880601101465>.

Aoki, Masahiko (2000). «Community Norms and Embeddedness: A Game-Theoretic Approach». En: Aoki, Masahiko y Hayami, Yujiro (eds.). Communities and Markets in Economic Development [en línea]. Nueva York: Oxford University Press. $<$ http://dx.doi.org/10.1093/0199241015.003.0004>.

AXELROD, Robert (1996). La evolución de la cooperación: El dilema del prisionero y la teoría de juegos. Madrid: Alianza Editorial.

Barbera, Filippo (2005). «Social networks, collective action and public policy: The embeddedness idea reconsidered». En: Koniondos, Sokratis (ed.). Networks, Trust and Social Capital: Theoretical and Empirical Investigations from Europe. Aldershot: Ashgate.

Bicchieri, Cristina (2006). The Grammar of Society: The Nature and Dynamics of Social Norms [en línea]. Nueva York: Cambridge University Press. $<$ http://dx.doi.org/10.1017/s0266267108001727>.

Bourdieu, P. (2001). «El capital social: apuntes provisionales». Zona Abierta, 94/95: 83-87.

Bowles, Samuel y GinTis, Herbert (2002). «Social capital and community governance». The Economic Journal [en línea], 112, 419-436. $<$ http://dx.doi.org/10.1111/1468-0297.00077>.

Brondizio, Eduardo; Ostrom, Elinor y Young, Oran (2009). «Connectivity and the Governance of Multinivel Socio-Ecological System: The Role of Social Capital». Annual Review of Environment and Resources [en línea], 34, 253-278. <http://dx.doi.org/10.1146/annurev.environ.020708.100707>.

BurT, Ronald (2004). «Structural Holes and Good ideas». American Journal of Sociology [en línea], 110 (2), 350-399. $<$ http://dx.doi.org/10.1086/421787>.

Campos, Valentina y Ávila-García, Patricia (2013). «Entre ciudades y presas: Oposición campesina al trasvase de agua y la defensa del río Temascaltepec, México». Revista de Estudios Sociales [en línea], 46, 120-133. $<$ http://dx.doi.org/10.7440/res46.2013.12>.

Carrington, P.; Scott, J. y Wasserman, S. (2005). Models and Methods in Social Network Analysis [en línea]. Cambridge: Cambridge University Press. $<$ http://dx.doi.org/10.1017/cbo9780511811395>.

Chile Sustentable (2012). Conflictos por el agua en Chile: Entre los derechos humanos y las reglas del mercado [en línea]. Editado por Sara Larraín y Pamela Poo. $<$ htttp://www.chilesustentable.net/wpcontent/uploads/2010/06/conflictos_agua_ chile_urg>.

Coleman, James (1988a). «Social Capital in the Creation of Social Capital». American Journal of Sociology [en línea], 94, 95-120. $<$ http://dx.doi.org/10.1086/228943>.

- (1988b). «Free Riders and Zealots: The Role of Social Networks». Sociological Theory [en línea], 6 (1), 52-57. $<$ http://dx.doi.org/10.2307/201913>. 
- (2011). Fundamentos de teoría social [en línea]. Madrid: Centro de Investigaciones Sociológicas. $<$ http://dx.doi.org/10.5477/cis/reis.143.7>.

Cook, Karen; Hardin, Russell y Levi, Margaret (2005). Cooperation without trust? [en línea]. Nueva York: Russell Sage Foundation. <http://dx.doi.org/10.1093/sf/86.2.851>.

Della Porta, Donatella y Diani, Mario (2006). Social Movements: An introduction [en línea]. Oxford: Blackwell Publishing. <http://dx.doi.org/10.1093/oxfordhb/9780199678402.013.23>.

DiAni, Mario (2003a). «Introduction: Social Movements, Contentious Actions, and Social Networks: "From Metaphor to Substance"?». En: Diani, Mario y McAdam, Douglas (eds.). Social Movements and Networks: Relational Approaches to Collective Action [en línea]. Oxford: Oxford University Press. <http://dx.doi.org/10.1093/0199251789.003.0001>.

- (2003b). "Leaders" or Brokers?: Positions and Influence in Social Movement Networks». En: Diani, Mario y McAdam, Douglas (eds.). Social Movements and Networks: Relational Approaches to Collective Action. Oxford: Oxford University Press.

- (2011). "Social Movements and Collective Action». En: Carrington, Peter y Scotr, John (eds.). The SAGE Handbook of Social Network Analysis. Londres: SAGE.

Diani, Mario y Bison, Ivano (2004). «Organizations, coalitions, and movements». Theory and Society [en línea], 33, 281-309. <http://dx.doi.org/10.1023/b:ryso.0000038610.00045.07>.

Durston, John (2002). El capital social campesino en la gestión del desarrollo rural: Díadas, equipos, puentes y escaleras. Santiago de Chile: CEPAL.

Evans, Peter (1997). "Government Action, Social Capital, and Development: Reviewing the Evidence of Synergy». En: Evans, Peter (ed.). State-Society Synergy: Government and Social Capital in Development [en línea]. California: University California at Berkeley. <http://dx.doi.org/10.1016/0305-750x(96)00021-6>.

Freeman, Linton (2000). «La centralidad en las redes: Clarificación conceptual». Politica y Sociedad, 33, 131-148.

Gould, Roger (1993). "Collective action and Network Structure». American Sociological Review [en línea], 58 (2), 182-196. <http://dx.doi.org/10.2307/2095965>.

Granovetter, Mark (1973). «The Strength of Weak Ties». American Journal of Sociology [en línea], 81, 1287-1303. <http://dx.doi.org/10.1086/225469>.

- (1982). "The Strength of Weak Ties: A Network Analysis Revisited». En: Marsden, Peter y Lin, Nan (eds.). Social Structure and Network Analysis. Beverly Hills: SAGE.

- (1990). "The Old and the New Economic Sociology». En: Friedland, Roger y Roberston, Sandy (ed.). Beyond the marketplace: Rethinking Economy and Society. Nueva York: Aldine de Gruyter.

- (1992). "Problems of Explanations in Economics Sociology». En: NoHria, Nitin y EcCles, Robert (eds.). Networks and Organizations: Structure, form, and action. Boston: Harvard Business School Press.

Hedström, Peter; Sandell, Rickard y Stern, Charlotta (2000). «Mesolevel Networks and the Difussion of Social Movements: The Case of the Swedish Social Democratic Party». American Journal of Sociology [en línea], 106 (1), 145-172. <http://dx.doi.org/10.1086/303109>. 
Herreros, Francisco (2002). «¿Son las relaciones sociales una fuente de recursos?: Una definición del capital social». Papers, 67, 129-148.

- (2004). The Problem of Forming Social Capital: Why Trust? Nueva York: Palgrave.

Hijmans, Robert; Cameron, Susan; Parra, Juan; Jones, Peter y Jarvis, Andy (2005). International Journal of Climatology [en línea], 25, 1965-1978. <http://dx.doi.org/10.1002/joc.1276>.

Infanti, L. (2008). Danos hoy el agua de cada día. Carta pastoral. Vicariato Apostólico de Aysén, Chile.

Instituto Nacional de Estadística (INE) (2002). Censo de población 2002 [en línea]. $<$ http://www.inearaucania.cl/contenido.aspx?id_contenido $=17>$.

Kadushin, Ch. (2013). Comprender las redes sociales: Teorias, conceptos, hallazgos. Madrid: Centro de Investigaciones Sociológicas.

Kandori, Michihiro (1992). «Social Norms and Community Enforcement». Review of Economic Studies [en línea], 59 (1), 63-80. <http://dx.doi.org/10.2307/2297925>.

Levi, Margaret (2001). "Capital social y asocial: Ensayo crítico sobre Making Democracy Work, de Robert Putnam». Zona Abierta, 94/95, 105-119.

Lin, Nan (2005). "A Network Theory of Social Capital». En: Castiglione, D.; VAN Deth, D. y Wolleb, G. (eds.). Handbook of Social Capital. Oxford: Oxford University Press.

McAdam, D.; Tarrow, S. y Tilly, Ch. (2001). Dynamics of Contention [en línea]. Cambridge: Cambridge University Press. <http://dx.doi.org/10.1017/s0022381600004333>.

Miller, Luis (2007). "Coordinación y acción colectiva». Revista Internacional de Sociología [en línea], V. LXV (46), 161-183. <http://dx.doi.org/10.3989/ris.2007.i46.8>.

Mussetta, Paula (2010). Los conflictos por el agua en América Latina [en línea]. Santiago de Chile: Centro de Estudios y Programas Interamericanos. Documento de Trabajo, 23. <http://interamericanos.itam.mx/working_papers/23MUSSETTA.pdf>.

NAvarrete, Lourdes (2008). «Experiencias de acción colectiva frente a la problemática ambiental en México». Revista Mexicana de Ciencias Políticas y Sociales, L (203), $157-174$.

Olson, Mancur (1992). La lógica de la acción colectiva: Bienes públicos y la teoría de grupos. México D.F.: Limusa.

Ostrom, Elinor (1994). "Constituting Social Capital and Collective Action». Journal of Theoretical Politics [en línea], 6 (4), 527-562. <http://dx.doi.org/10.1177/0951692894006004006>.

- (2000a). «Social Capital: A fad or a fundamental concept?». En: DAsGupta, Partha y Serageldin, Ismail (eds.). Social Capital: A Multifaceted Perspective [en línea]. Washington D.C.: World Bank. <http://dx.doi.org/10.1596/978-0-8213-5004-1>.

- (2010a). "Analyzing collective action». Agricultural Economics [en línea], 41 (1), $155-166$. <http://dx.doi.org/10.1111/j.1574-0862.2010.00497.x>.

- (2010b). «Beyond Markets and States: Polycentric Governance of Complex Economic Systems». American Economic Review [en línea], 100 (3), 641-72. <http://dx.doi.org/10.1257/aer.100.3.641>. 
Putnam, R. (2000). Per fer que la democràcia funcioni: La importància del capital social. Barcelona: Proa.

Rouanet, Juan; Romero, Oriella y Demanet, Rolando (1988). «Áreas agroecológicas de la IX Región: Descripción». IPA-Carillanca, 7 (1), 18-24.

Sсотт, John (2000). Social Network Analysis: A handbook [en línea]. Londres: Sage Publications. <http://dx.doi.org/10.1177/000169939403700408>.

Streeter, Calvin y Gillespie, David (1992). «Social Network Analysis». En: GillesPIE, David y Glisson, Charles (eds.). Quantitative Methods in Social Work: State of the Art. Nueva York: Haworth Press.

TARROW, Sidney (2011). El poder en movimiento: Los movimientos sociales, la acción colectiva y la política [en línea]. Madrid: Alianza Editorial. <http://dx.doi.org/10.17141/iconos.13.2002.635>.

Tilly, Charles y Tarrow, Sidney (2007). Contentious Politics [en línea]. Boulder: Paradigm Press. $<$ http://dx.doi.org/10.1353/jsh.2008.0052>.

UNESCO (2012). Managing Water Under Uncertainty and Risk [en línea]. <http:// www.unesco.org/new/fileadmin/MULTIMEDIA/HQ/pdf/WWDR\%20 Volume\%201-Managing\%\%20Water\%20under\%20Uncertainty\%20and\%20 Risk.pdk>.

Wasserman, S. y Faust, K. (2013). Análisis de redes: Métodos y aplicaciones. Madrid: Centro de Investigaciones Sociológicas.

Woolcok, Michael y Narayan, Deepa (2000). «Social Capital: Implications for Development Theory, Research, and Policy». The World Bank Research Observer [en línea], 15 (2), 225-249. <http://dx.doi.org/10.1093/wbro/15.2.225>.

YÁÑez, Nancy y Molina, Raúl (2011). Las aguas indígenas en Chile. Santiago de Chile: Editorial LOM.

Zubcsek, Peter; Chowdhury, Imran y Katona, Zsolt (2014). «Information communities: The network structure of communication». Social Networks [en línea], $38,50-62$. <http://dx.doi.org/10.1016/j.socnet.2014.02.001>. 